\title{
De la "violencia» (de género) a las "cifras de la violencia»: una cuestión política
}

\author{
RAQUEL OSBORNE \\ UNED \\ rosborne@poli.uned.es
}

Recibido: 04.03.2008

Aceptado: 16.06 .2008

\begin{abstract}
Hay una forma de incertidumbre que no tiene que ver con los resultados sino con los principios, y a mi modo de ver afecta de lleno a las ciencias sociales. No se refiere a lo que vemos cuando observamos, sino a si miramos en la dirección adecuada, si sabemos ver (Durán, 2007).
\end{abstract}

\section{INTRODUCCIÓN}

Aunque inicialmente parece que hoy en día todo el mundo estará de acuerdo en qué consiste la violencia de género, en la gravedad del fenómeno y en el número de muertes que se produce por su causa — por mencionar sólo algunas de las cuestiones que habitualmente se suscitan en torno a este tema-, lo cierto es que sólo se ha empezado a poder contabilizar el fenómeno a partir de la conceptualización de lo que se entendía por tal.

Uno de los grandes logros del feminismo contemporáneo es que cambió nuestra comprensión de la sexualidad y de las relaciones entre mujeres y varones al identificar la violencia sexual como un elemento importante en el mantenimiento de la subordinación de las mujeres, al proporcionarles nuevas vías para la comprensión de su situación y al impulsar la creación de recursos para combatir

${ }^{1}$ El presente artículo ha sido publicado en la revista Empiria (Revista de Metodología de Ciencias Sociales), n. ${ }^{\circ}$ 15, enero-junio 2008. Se ha realizado en el marco del proyecto de investigación de referencia I+D+I BFF2003-00655 aprobado en el marco del Plan Nacional de Investigación Científica, Desarrollo e Innovación Tecnológica 2000-2003. Debo agradecer a Sara Barrón y a Begoña Pernas por sus comentarios críticos ante la lectura del borrador del presente artículo y a Rosa Gómez Redondo y a Elena Robles su ayuda técnica en relación con alguna de las estadísticas aquí mencionada. 
dicha violencia. Ha conseguido que se entienda la violación no como un delito contra el honor de las familias sino como un asalto violento cometido contra las mujeres no sólo por extraños sino también por los maridos, padres o personas cercanas. Ha promovido las denuncias por malos tratos a las mujeres, insistiendo en la dejación de su consideración como un asunto privado y personal entre los miembros de una pareja. De igual manera, ha acuñado el concepto de acoso sexual, que destapa la realidad de los avances sexuales indeseados que generaciones de mujeres han tenido que sufrir, principalmente en el trabajo.

Pero esta tarea no era suficiente. Hacía falta el reconocimiento al más alto nivel para que los Estados tomaran cartas en el asunto, y ello tuvo lugar con la $D e$ claración de Naciones Unidas sobre la Eliminación de la Violencia contra la Mujer de 1993, cuyo artículo 1 considera violencia contra las mujeres a «todo acto de violencia basado en la pertenencia al sexo femenino que tenga o pueda tener como resultado un daño o sufrimiento físico, sexual o psicológico para la mujer, incluidas las amenazas de tales actos, la coerción o la privación arbitraria de la libertad, tanto si se producen en la vida pública como en la privada». Pero para que se produjera el salto del macronivel de decisión que representa la ONU a la política del día a día de cada país tienen que ocurrir más cosas.

En España tuvieron lugar al menos tres factores añadidos:

- los años noventa ven aflorar el problema de la violencia de pareja, si bien desde los años setenta habían comenzado las movilizaciones en relación a las agresiones sexuales. Una de las caras más visibles del activismo feminista en los años noventa era el dedicado a la problemática de las separaciones y divorcios, lugar fundamental de la emergencia de esta violencia, oculta habitualmente;

- fruto de la intensa movilización los medios de comunicación de masas acaban por interesarse por el fenómeno: a partir de 1997 se da el salto del entorno feminista a los medios de comunicación de masas tras la denuncia en televisión por Ana Orantes de su crónica situación de maltrato y su posterior brutal asesinato a manos de su marido ${ }^{2}$;

- a partir de entonces, las instituciones encargadas de la «problemática de la mujer» — véase principalmente el Instituto de la Mujer — toman cartas en el asunto: en 1998 en el marco del III Plan de Igualdad de Oportunidades entre Mujeres y Hombres se crea el Plan de Acción contra la Violencia Doméstica, que por primera vez plantea el trabajo conjunto de las distintas administraciones para establecer una serie de medidas que den respuesta a la violencia en este ámbito (Vives 2001). El plan establecía seis áreas de actuación, entre ellas una de investigación, que comenzó a elaborar «un módulo estadístico para recoger los datos referidos

${ }^{2}$ No es nuestra intención aquí analizar las razones por las que los medios de comunicación modifican su postura en torno a esta problemática, como tampoco se pretende idealizar su papel. Para un análisis sobre violencia de género y medios de comunicación véase Fernández Díaz (2003).

EMPIRIA. Revista de Metodología de Ciencias Sociales. N. ${ }^{\circ}$ 15, enero-junio, 2008, pp. 99-124. ISSN: 1139-5737 
a la violencia así como un manual con normas estadísticas de actuación coordinadas y uniformes que deben seguir en la recogida de estos datos tanto la Guardia Civil como el Cuerpo General de Policía». En el marco de este área se realiza también una «Macroencuesta a nivel nacional, sobre la violencia contra las mujeres, para conocer cuántas mujeres son víctimas de actos de violencia, malos tratos y/o abusos sexuales y las causas que contribuyen a su aparición» (Ibid.:88). Tres de estas encuestas (2000, 2002 y 2006) han sido realizadas hasta la fecha. Estas iniciativas tieneN lugar, por tanto, sólo a partir del momento en que se reconoce política y socialmente la gravedad de esta violencia.

Sin estos supuestos previos no hay contabilidad organizada del fenómeno de la violencia contra las mujeres. Llevar una contabilidad eleva el fenómeno de anécdota a categoría, conduciendo a su mayor visibilidad. La violencia hoy es más visible, pues, y ello tiene mucho que ver con el cambio en la mirada, tal y como refleja la cita del comienzo de Durán. Si nos atenemos, en consecuencia, a esta diferente forma de mirar hemos de tener en cuenta siempre como punto de partida la distinción entre «la violencia» $\mathrm{y}$ «las cifras de la violencia»: entre la definición «abstracta» de la violencia y las cifras median los «indicadores» de qué se considera violencia, y ello depende en buena parte, en primer lugar, de la toma de conciencia del problema y, en segundo lugar, de los diversos intereses en liza; en definitiva, es una cuestión política.

A partir de ahí, de lo que sí podemos estar seguros es de que las cifras de la violencia han aumentado, y ello por diversas razones, algunas de las cuales citaremos a título de ilustración:

a) Por ampliación de a quiénes se considera victimarios y víctimas: de maridos a parejas de hecho a «exes» de todo tipo, incluyendo novios. Así, de 2001 a 2002 las denuncias interpuestas por mujeres —hasta el año 2002 sólo se incluían datos relativos a mujeres- pasaron de 24.158 a $43.213^{3}$.

b) Debido a la creación de nuevas leyes, por ejemplo la Orden de Protección de 2003, que contribuyó a que se incrementaran las denuncias — promulgada a finales del mes de julio, es decir, vigente durante sólo 5 meses, las denuncias en ese año pasaron de 43.213 a $50.088-^{4}$. Del mismo modo, a partir de enero de 2004, la introducción de nuevos tipos delictivos y la modificación de alguno de los ya existentes (muchas de las infracciones consideradas hasta entonces como «faltas» pasan a tipificarse como «delitos») supuso un aumento del número de víctimas ${ }^{5}$.

\footnotetext{
3 Datos del Ministerio del Interior reelaborados por el Instituto de la Mujer. http://www.mtas.es/ mujer/mujeres/cifras/violencia/denuncias_tablas.htm

4 Datos del Ministerio del Interior reelaborados por el Instituto de la Mujer. http://www.mtas.es/ mujer/mujeres/cifras/violencia/denuncias_tablas.htm

5 http://www.mtas.es/mujer/mujeres/cifras/violencia/denuncias.htm.
} 
c) Por ampliación de la definición de la conducta a tener en cuenta o a perseguir:

- en el acoso sexual, redefinido como acoso leve (mayores cifras), grave y muy grave (Inmark 2006);

- en el maltrato, al estilo de las Macroencuestas 2000/2002/2006 del Instituto de la Mujer, que distinguen entre maltrato declarado y maltrato «técnico» (con cifras más elevadas).

Desde sus inicios la contabilidad de la violencia ha ido acompañada de controversias acerca de cuál es la manera más acertada de efectuarla. Los intereses mueven a los actores sociales en una pugna de poder cuyo resultado determina que se vaya escogiendo una forma u otra de contar más allá de los episodios «reales» de violencia. Ello hace que, a veces, y desde el punto de vista de las ciencias sociales, la metodología empleada sea susceptible de análisis críticos que nos iluminen sobre la evolución, pluralidad e implicaciones de los métodos utilizados. En suma, que nos alerten sobre las razones y la idoneidad de los mismos. Algunas de estas controversias atraerán nuestra atención en este artículo:

a) La que implica una tensión recurrente entre los grupos líderes en la movilización feminista contra la violencia y la respuesta institucional ante la problemática en cuestión en torno a la contabilidad de las cifras de la violencia. Referiremos para ello dos momentos en que se ha plasmado esa tensión, el primero desde la segunda mitad de los años noventa del pasado siglo hasta su resolución hacia el año 2002, y el segundo que se desarrolla todavía en el presente.

b) La que se sigue de la investigación conocida como La Macroencuesta —en sus sucesivas ediciones de 2000, 2002 y 2006-, auspiciada por el Instituto de la Mujer, que supuso una ampliación de los supuestos de lo que se entiende por maltrato y el subsiguiente aumento de las cifras del mismo.

\section{LAS CIFRAS DE LA VIOLENCIA A DEBATE}

\subsection{La violencia, un asunto de intervención pública}

Mucho se ha tardado en reconocer la importancia y la gravedad de la violencia contra las mujeres. Un caso paradigmático ha sido la dificultad de entenderla, en los casos de guerras, como una estrategia integrada en las políticas de Estado para vencer al enemigo. Según Terrasson (2003), aunque ya en 1914 las violaciones fueron denunciadas como crímenes de guerra, no se hallaban insertas en esquemas interpretativos más amplios por no ser vistas como una práctica sistemática de terror. En el análisis pre-feminista contemporáneo no existía el 
punto de vista de las víctimas ni, por tanto, la preocupación por las secuelas psíquicas de la violencia sexual. Se hablaba de víctimas, ciertamente, pero las mujeres eran siempre sospechosas de un posible consentimiento y, por lo tanto, también entraban las nociones de mancha, deshonor y hasta de muerte social como algo lógico que podía llevar a las mujeres violadas, a menudo con hijos producto de las violaciones, incluso al suicidio. Las comisiones —una británica y otra francesa- que condenaron estos hechos lo hicieron en tanto que excesos individuales, pero se mostraron incapaces de pensarlas en el marco de las grandes atrocidades del enemigo. En consecuencia, sin una interpretación sistémica del asunto, unido a la incomodidad de hablar de sexo en una época que no había «descubierto» el componente de violencia y odio de las agresiones sexuales contra las mujeres, la cuestión cayó - caía una y otra vez- en el olvido. Habrá que esperar al conflicto de los Balcanes - comienzos de la década de los años noventa del siglo XX - para que se reconociera la importancia y la gravedad de estas agresiones. Y no es que hasta entonces no hubiera datos suficientes en los distintos conflictos armados conocidos en torno a los abusos sexuales de todo tipo a las mujeres, pero o bien se habían escamoteado los datos a la opinión pública, o todavía peor, existía una tolerancia real hacia las agresiones (Osborne y Justo Suárez 2004) ${ }^{6}$.

Teresa de Lauretis, por su parte, habla de la «retórica de la violencia», noción foucaultiana que indica un orden de violencia del lenguaje, esto es, que nombra ciertos comportamientos y hechos como violentos, pero no a otros, así como construye objetos y sujetos de violencia y de este modo a la violencia como un hecho social (de Lauretis 1987). «Hace sólo hace unas décadas, el término "violencia familiar" habría carecido de sentido. Así, el abuso infantil, el maltrato a las esposas y el incesto habrían sido entendidos pero no reconocidos como serios problemas sociales» (Wini Breines y Linda Gordon (1983), en de Lauretis op. cit.: 33). Por tanto, según lo definamos entenderemos una cosa u otra y abarcaremos más o menos aspectos del fenómeno que nos ocupa.

Tal y como hemos comentado, desde los años setenta el feminismo de la llamada segunda ola empezó a comprender que una de las formas de control de las mujeres se llevaba a cabo por medio del ejercicio de la violencia, o la amenaza de su utilización. En España, en los años noventa, la amplificación mediática del fenómeno trasladó a las páginas «serias» de la prensa escrita y a un lugar central en los noticieros audiovisuales la información sobre las muertes de mujeres producidas por la violencia masculina.

La toma de conciencia social supone, además, movilizaciones para hacer visible la violencia que se entiende como «escondida» («las denuncias son sólo la punta del iceberg, la prueba es que muchas de las muertes no pasan por la denuncia...» son afirmaciones que se vienen realizando desde hace más de diez años) y lograr por este camino poder intervenir sobre ella.

6 Sobre la construcción de los marcos de interpretación en relación a la violencia de género véase de Miguel Álvarez (2003).

EMPIRIA. Revista de Metodología de Ciencias Sociales. N. ${ }^{\circ}$ 15, enero-junio, 2008, pp. 99-124. ISSN: 1139-5737 
En este objetivo confluyen intereses otrora dispares:

a) Los de las instituciones, véase el Instituto de la Mujer a finales de los noventa, época del gobierno del Partido Popular. El combate contra la violencia, inicialmente denominada doméstica, pasa a la primera fila del debate político, y el Partido Popular la convierte en una prioridad de su política para con las mujeres con la puesta en marcha del ya citado Plan de Acción contra la Violencia Doméstica de 1998. Se cumplen así dos objetivos: se capitaliza el nuevo interés social hacia esta problemática, dando la impresión de realizar política «feminista» desde el poder, mientras que por otro lado no se atienden muchas otras reivindicaciones de las mujeres - mayor participación política, derechos laborales, derechos sexuales y reproductivos y acciones positivas ${ }^{7}$, entre otras-.

b) Los del feminismo, desmovilizado desde finales de los años ochenta/principios de los noventa, que se re-configura y re-moviliza, ganando más espacio social con la promoción de la denuncia del tema de la violencia contra las mujeres (Marugán y Vega 2001).

\subsection{Las cifras, condición para la intervención}

2.2.1. Las cifras representan el aspecto «técnico» de esta visibilización. La contabilidad aumentará o disminuirá dependiendo de cómo preguntemos o qué supuestos incluyamos bajo la rúbrica de violencia. Y lo que se ha venido haciendo en España en paralelo a la toma de conciencia en torno al problema es modificar los indicadores de violencia.

A mediados de los años noventa comienzan a conocerse las estadísticas del Ministerio del Interior sobre este tema. A finales de la década se pueden observar las discrepancias entre, por una parte, las cifras de las asociaciones de mujeres - en particular por parte de la Federación de Mujeres Separadas y Divorciadas, pionera en España en ocuparse de las mujeres en situaciones de violencia- y las proporcionadas por el Instituto de la Mujer, cuya fuente provenía del Ministerio del Interior.

La metodología de la Federación en cuanto a la recopilación de datos sobre la violencia de pareja con resultado de muerte era sencilla: hacer un seguimiento sistemático de la prensa diaria y registrar los casos de asesinatos de mujeres por parte de las parejas masculinas, ya fuera en situaciones de conyugalidad o fuera de ella, en relaciones vigentes o pretéritas. Interior, por su parte, se limitaba

\footnotetext{
${ }^{7}$ Por razones de conveniencia electoral — con elecciones generales previstas para el 9 de marzo de 2008-, no obstante, en enero de ese mismo año el Partido Popular, siempre contrario a la discriminación positiva, ha comenzado a hacer sus primeras propuestas en este sentido. Vid. Rafael Méndez, «Rajoy promete bajar 1000 euros los impuestos a todas las trabajadoras (El PP abraza la discriminación positiva tras recurrir la Ley de Igualdad)», El País, domingo 13 de enero de 2008, España, p. 16.
} 
a contabilizar la violencia ejercida por los cónyuges o parejas de hecho (incluidas estas últimas desde 1998), sin tener en cuenta la que tenía lugar por parte de excónyuges, y mucho menos entre novios, exnovios o pretendientes; además, no incluía los datos de la Ertxantxa y de los Mossos d'Squadra. Previsiblemente, siempre resultaban inferiores las cifras de Interior. Un ejemplo nos dará la idea clara: mientras que en 1999 el Instituto de la Mujer manejaba las cifras de 42 mujeres muertas (Vives 2001) ${ }^{8}$, la Federación manejaba la de 68 mujeres.

Sin embargo, conviene recordar que por las mismas fechas el Instituto de la Mujer realizó la primera de las Macroencuestas que viene efectuando con una cierta periodicidad. En ella se pretendía estudiar el número de actos violentos, especialmente en el ámbito doméstico, en los que las víctimas eran mujeres, violencia perpetrada «por alguna de las personas que convive en su hogar, o por su novio» (Vives 2001:89). Es decir, el Instituto comenzaba a modificar por entonces sus criterios aun cuando todavía ello no se viera reflejado en sus estadísticas, que provenían del Ministerio del Interior.

Haciéndose eco de las insuficiencias señaladas por los grupos feministas, en 2002 el Ministerio del Interior -lo cual fue recogido por el Instituto de la Mujer en sus estadísticas- cambia algunos de los criterios manejados hasta entonces en el recuento de las muertes. Se comienza a computar las causadas por otras parejas más allá del matrimonio o las parejas de hecho legales, es decir, por los excónyuges, excompañeros sentimentales, novios o exnovios. Otra novedad consistió - tal y como se veía reflejado en la web del Instituto en julio de $2007^{9}$ aunque no se mencionaba la fecha de esta modificación - en la inclusión de los fallecimientos que tienen lugar con posterioridad a las primeras 72 horas desde la comisión del delito. Igualmente se subsana el déficit de información en las comunidades autónomas antes mencionadas: en septiembre de 2006 - otra de las fechas en que esta autora consultó la web del Instituto de la Mujer - se decía que el Instituto estaba teniendo en cuenta los datos que le proporcionaban las organizaciones de mujeres ${ }^{10}$ — que, recordemos, al efectuar su recuento con las noticias aparecidas en la prensa diaria nacional no padecían esta limitación «territorial»- Algún tiempo después -julio de 2007- ya constaba como propia una forma de cuantificación basada «en un sistema mixto y unificado, en el que, partiendo de las noticias aparecidas en los medios de comunicación, que son utilizados como "sistema de alerta", cada uno de los casos es, posteriormente, contrastado con los datos provenientes del Ministerio del Interior y, en un futuro, del ámbito judicial» ${ }^{11}$. Hasta aquí, pues, el relato de la primera «tensión» de la que

${ }^{8}$ En febrero de 2008 la web del Instituto de la Mujer da para 1999 otra cifra -de 54 muertaspero porque ha reconstruido a posteriori sus propias cifras por medio de combinar noticias de los medios de comunicación y los del Ministerio del Interior. Con todo, siguen sin concordar con las proporcionadas en aquel entonces por las Mujeres Separadas. http://www.mtas.es/mujer/mujeres/ cifras/tablas/W805b.XLS

${ }^{9}$ En febrero de 2008 continúa colgada la misma afirmación.

${ }^{10}$ Esta información ya no aparecía mencionada en la web en julio de 2007.

${ }^{11} \mathrm{http} / / /$ www.mtas.es/mujer/mujeres/cifras/violencia/muertes.htm 
hablábamos al principio, resuelta con la adopción institucional de los criterios de las organizaciones de mujeres.

2.2.2. El testigo del cómputo realizado inicialmente por la ya citada Federación de Asociaciones de Mujeres Separadas y Divorciadas fue recogido por otras organizaciones y finalmente asumido por la Red de Organizaciones Feministas (REF) contra la Violencia de Género, a cuya estructura pertenece la Fundación Mujeres. Este grupo presentó en 2003 un Informe sobre violencia contra

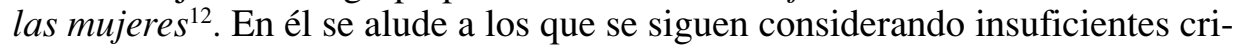
terios de Interior. La Fundación pide que «se recojan no sólo episodios de violencia en función de la relación de parentesco, sino de la causa y el objetivo que persigue esta violencia», porque a su juicio se están dejando fuera formas de violencia que se ajustan a la definición que Naciones Unidas hace sobre «violencia contra las mujeres» y se incluyen otras cuyo motivo es ajeno a una cuestión de género $^{13}$. De hecho, los datos oficiales del primer semestre de 2003 hablan de 37 muertes mientras que la REF consigna 45 víctimas. Unos meses después la Red Feminista amplía en otro informe ${ }^{14}$ la contabilidad de la violencia a otras relaciones familiares más allá de la erótico-afectiva: suegras, hijas, hijastras y madres. Rechaza, por otra parte, ceñirse simplemente al ámbito familiar en que se produce la violencia, incluyendo los casos encontrados de violencia no familiar (asalto sexual, tráfico de mujeres etc.). Los desfases entre ambas estadísticas se repiten en años posteriores.

En 2004 tiene lugar un inesperado vuelco en el Gobierno de la nación que, tras las elecciones generales de marzo, pasa a ser socialista. El nuevo Gobierno anuncia entre sus prioridades las políticas sociales, creando un nuevo alto cargo en el seno del Ministerio de Trabajo y Asuntos Sociales - la Secretaría General de Políticas de Igualdad-. La primera ley promulgada por este Gobierno en esa legislatura fue la Ley Orgánica 1/2004, de 28 de diciembre, de Medidas de Protección

${ }^{12}$ Fundación Mujeres, Informe sobre violencia contra las mujeres en España. Tasas y tendencias de Homicidio/Asesinato 1999/2003 (www.mujeresenred.net/violencia.htm)

${ }^{13}$ El artículo 2 de la Declaración de Naciones Unidas sobre la Eliminación de la Violencia contra la Mujer de 1993 especifica qué actos de violencia de género se incluyen bajo esta categoría:

a) «La violencia física, sexual y psicológica que se produce en la familia y en el entorno más próximo, incluidos los malos tratos a mujeres e hijos, el abuso sexual de las niñas en el hogar, la violencia relacionada con la dote, la violación marital, la mutilación genital femenina y otras prácticas tradicionales nocivas para las mujeres, los actos de violencia perpetrados por otros miembros de la familia y la violencia relacionada con la explotación.

b) La violencia física, sexual y psicológica perpetrada dentro de la comunidad en general, incluidas la violación, el abuso sexual, el acoso y la intimidación sexuales en el trabajo, en instituciones educacionales y en otros lugares, el tráfico de mujeres y la prostitución forzada;

c) La violencia física, sexual y psicológica perpetrada o tolerada por el Estado, donde quiera que ocurra».

${ }^{14}$ Dossier: Violencia contra las mujeres con resultado de muerte. (Estudio sobre noticias aparecidas en prensa) (2003) (Red estatal de organizaciones feministas (12pp.). http://www. refeminista.org/ 
Integral contra la Violencia de Género, denominada comúnmente Ley Integral, aprobada por unanimidad en el Congreso de los Diputados: ningún partido quiso quedarse fuera del consenso. No obstante, años después se mantienen algunas discrepancias entre las instituciones y las organizaciones de mujeres en torno a los criterios para la recopilación de los datos de las agresiones con resultado mortal.

En 2006 las muertas registradas por el Instituto de la Mujer ascendían a 68. Otros datos, también oficiales, relatan que un total de 18 mujeres fueron asesinadas en el mismo año por padres, hijos u otros familiares (El País, Sociedad, 501-2007). A ello, según la REF, habría que sumar las producidas por agresión sexual, tráfico de mujeres y prostitución. El número de asesinadas ascendería, según estos criterios, a $93^{15}$. Los casos no incluidos en las estadísticas del Instituto de la Mujer no están amparados por la Ley Integral —aunque sí lo están por el Código Penal- y «por el momento» no está previsto cambiar la norma según declaraciones de Soledad Murillo, Secretaria General de Políticas de Igual$\mathrm{dad}^{16}$. Con todo, la página web del Instituto de la Mujer proclamaba, en julio de $2007^{17}$, lo siguiente: «De forma progresiva, iremos incorporando nuevas variables, así como otras tablas, relativas al número de mujeres muertas por violencia de género en ámbitos distintos al de las relaciones de pareja/expareja (resto de relaciones familiares o sin existencia de vínculo familiar alguno), si bien, en relación con estos casos, existen, todavía, dificultades metodológicas importantes que aún habrá que resolver» ${ }^{18}$.

No sabemos si esa incorporación a la estadística irá acompañada del cambio en la ley que pospone Murillo. La cuestión no es baladí: supone incluir o excluir de la contabilidad nada menos que a 18 mujeres. Significa re-pensar qué se entiende por violencia de género más allá de que estemos hablando de violencia contra las mujeres, al igual que de violencia que tiene lugar en el ámbito doméstico. Abundaremos en ello en la segunda parte de este artículo. Entretanto, llamaremos la atención sobre algunos casos en que la agresión tiene lugar en el seno de la pareja con resultado de muerte y se efectúa de hombre a mujer pero en los que, en nuestra opinión, no deberían contabilizarse como violencia de género. Al menos una de las muertes a manos de la pareja contabilizadas como violencia de género en 2006 no cabe por menos que calificarla de eutanasia «informal» - fuera de los cauces médicos- por parte del marido (89 años), integrante de un matrimonio calificado de ejemplar por los vecinos, a su mujer, también octogenaria pero víctima de Alzheimer y osteoporosis avanzada ${ }^{19}$. Esto incide, como podemos observar, en el tema de cómo se clasifican las muertes: en

15 http://www.redfeminista.org/searchnoticias.asp?id=prostitucion2006.

${ }^{16}$ El País, «18 mujeres fueron asesinadas en 2006 por padres, hijos u otros familiares», El País, Sociedad, 5 de enero de 2007.

${ }_{17}$ El mismo texto puede leerse en febrero de 2008.

${ }^{18}$ Cabe preguntarse: ¿no habrá, además, preocupaciones presupuestarias?

19 Oviedo, 14 de diciembre de 2006, «Mata a su mujer, enferma de Alzheimer, y se suicida. Él tenía 89 años, ella, 80». http://actualidad.terra.es/articulo/html/av21272623.htm. Para un comentario crítico, vid. José Tovar Larrueca, «Violencia y amor», El País, Opinión, 15 de diciembre de 2006.

EMPIRIA. Revista de Metodología de Ciencias Sociales. N. ${ }^{\circ}$ 15, enero-junio, 2008, pp. 99-124. ISSN: 1139-5737 
este caso puede considerarse como un acto de amor $-\mathrm{y}$ de desesperación ${ }^{20}$ pero con el resultado de muerte, ¿es válido incluirlo en las estadísticas de muerte por violencia de género por el hecho de que coincide en que ha sido una violencia de hombre a mujer? En 2007 tuvo lugar un suceso terrible, en el que un hombre mató a su madre, su esposa y su hijo y atacó a otras dos hijas en Toledo, para acabar suicidándose, parricidio calificado como uno de los más trágicos ocurridos en España en lo que va de siglo. Aparentemente, un caso más de violencia de género. Pero cuando se lee la letra pequeña vemos, por una parte, cómo este hombre, enfermo él mismo, llevaba media vida cuidando a casi toda su familia, aquejada de distintos y graves problemas de salud, y por otra, cómo los vecinos no daban crédito a lo ocurrido puesto que el presunto parricida «llevaba toda la vida luchando por su familia», a la que trataba «muy bien» y con la que estaba volcado ${ }^{21}$. Si tenemos en cuenta los criterios manejados, pongamos por caso, por la Fundación Mujeres, en los que se pedía que se recogieran «no sólo episodios de violencia en función de la relación de parentesco, sino de la causa y el objetivo que persigue esta violencia» estos supuestos no deberían ser incluidos como violencia de género. No obstante los dos episodios narrados han sido incluidos en la contabilidad que la Red de Organizaciones Feministas contra la Violencia de Género presenta en su página web, Red que, como comentamos más arriba, incluye a la Fundación Mujeres.

\section{LAS MACROENCUESTAS (2000, 2002, 2006)}

\subsection{La propuesta del Instituto de la Mujer: la ampliación del concepto de maltrato}

Además de redefinir conceptos, el feminismo se ha dedicado en los últimos años a expandirlos poco a poco, a ampliar su contenido, como hemos entrevisto con algunos ejemplos en la primera parte de este artículo. En esta segunda parte analizaremos sobre todo la noción de maltrato técnico — utilizado por primera vez en la Macroencuesta 2000 - , las cifras que de ella se derivan y nos preguntaremos sobre lo acertado —o no- de su producción/utilización ${ }^{22}$.

${ }^{20} \mathrm{Si}$ en España fuera legal la eutanasia según la voluntad de quien la solicita el resultado contable de estas dos muertes habría sido muy otro.

${ }^{21} \mathrm{http} / / / w w w . n o r t e c a s t i l l a . e s / 20070217 / v i d a / m a t a-c u a t r o-p e r s o n a s-m i s m a \_200702171649$. html. Jesús Duva, «Un hombre mata a su madre, su esposa y su hijo y ataca a otras dos hijas en Toledo», El País, 18 de febrero de 2007, Sociedad p. 40.

${ }^{22}$ Se incluyen los datos de la ficha técnica de las Macroencuestas de 2000 y 2006, por ser las que más se utilizan en el presente artículo:

Universo: mujeres españolas (residentes en España, 2006) de 18 ó más años.

Ámbito: Nacional, incluidos los territorios de Ceuta y Melilla.

Muestra: 20.552 entrevistas (32.426 en 2006), con un error estadístico de $+0,7 \%(0,61 \%$ en 2006) para un nivel de confianza del $95,5 \%$ (dos sigma) y p/q $=50 / 50$. 
La forma de abordar conceptualmente el problema del maltrato influirá decisivamente en los resultados que obtengamos. Centraremos nuestro análisis preferentemente en la primera Macroencuesta (Instituto de la Mujer 2000) por el impacto que tuvo en su momento - los grandes titulares de la prensa así lo reflejan-y porque fue la que inauguró la serie, que no ha sufrido particulares cambios en las sucesivas ediciones ${ }^{23}$.

La encuesta nace en el marco del Plan de Acción contra la Violencia Doméstica de 1998 como la iniciativa más destacada en el área de investigación prevista por el Plan. Surge con el objetivo de cuantificar los actos violentos contra las mujeres en el ámbito doméstico, «los factores determinantes en la aparición de los mismos, las consecuencias personales y sociales que acarrea el sufrir dichos actos y, finalmente, la opinión de las víctimas sobre las posibles medidas a tomar por parte de la Administración para erradicar la violencia y paliar sus efectos» (Vives 2001: 12).

A lo largo del informe, se hace referencia a dos tipos de maltrato: maltrato técnico y maltrato declarado. Maltrato tipo A «técnico»: «Las mujeres tipo A son aquéllas que afirman que, en la actualidad, alguna persona de su hogar (o su novio/pareja que no convive con ella) es causante, "frecuentemente" o "a veces", de al menos una» de las trece situaciones que se describen más abajo (Instituto de la Mujer 2000: 10).

Maltrato tipo $B$ «declarado»: se incluyen bajo este apartado a las mujeres «que afirman haber sufrido alguna situación durante el último año por la que se hayan considerado maltratadas por algún familiar, por su novio o por alguna persona de las que conviven en su hogar, es decir, se autoclasifican como maltratadas» (Ibid.: 10).

El informe extrae las siguientes conclusiones:

— Mujeres tipo A: El 12,4\% — 1.865.000 mujeres_ admite en el momento de la encuesta lo que se ha dado en denominar «maltrato técnico». «Es decir, aunque ellas no se hayan reconocido explícitamente como maltratadas, han sido consideradas "técnicamente" como tales al admitir, mediante una batería de preguntas, que su pareja les insulta, amenaza o controla de forma frecuente» (Vives 2001: 89).

- Mujeres tipo B: «El 4,2 de las mujeres españolas mayores de 18 años declara haber sido víctima de malos tratos durante el último año por algu-

Tipo de muestreo: polietápico, estratificado, con selección aleatoria de las unidades secundarias (municipios) y selección de las unidades últimas (mujeres.

Distribución de la muestra: semiproporcional, con una cuota fija de 300 entrevistas por Comunidad Autónoma y el resto proporcional a la población de cada una de ellas (excepción hecha en 2006 de las Comunidades Autónomas que han querido aumentar más su muestra). Por tamaño de hábitat la distribución es proporcional dentro de cada autonomía.

Entrevista: telefónica mediante sistema CATI.

${ }^{23}$ Datos de las otras dos macroencuestas de 2002 y 2006 serán citados circunstancialmente cuando resulte pertinente para la argumentación.

EMPIRIA. Revista de Metodología de Ciencias Sociales. N. ${ }^{\circ}$ 15, enero-junio, 2008, pp. 99-124. ISSN: $1139-5737$ 
na de las personas que convive en su hogar, o por su novio, lo que representa un total de 640.000 mujeres entre los 15.028 .000 de mujeres españolas de 18 o más años» (Ibid.: 89). Es decir, se autoclasifican como maltratadas.

En la mayor parte de los casos declarados en la Macroencuesta -el 52\%-, el agresor es el marido, la pareja o la expareja, correspondiendo el resto a maltrato por otros miembros de la familia: un $12,5 \%$ de las que se declaran maltratadas lo son por los hijos/as, un $11 \%$ por el padre, un $11,4 \%$ por la madre, un $17,9 \%$ por hermanos/as y un $13,8 \%$ por otras personas, familiares o no familiares. Por lo que respecta a las mujeres consideradas como «técnicamente» maltratadas, el 74,2\% lo son a manos del marido, la pareja o la expareja, el 14,1\% por los hijos/as, un $13,5 \%$ por el padre, un $12,8 \%$ por la madre, un 3,6\% por hermanos/as y un 3,1\% por otras persona, familiares o no familiares.

Las mujeres tipo A son aquéllas que han respondido «frecuentemente» $\mathrm{O}$ «a veces» a alguna de las trece frases reseñadas a continuación:

1) Le impide ver a la familia o tener relaciones con amigos, vecinos.

2) Le quita el dinero que Vd. gana o no le da lo suficiente que necesita para mantenerse.

3) Le insulta o amenaza.

4) Decide las cosas que Vd. puede o no hacer.

5) En ciertas ocasiones, le produce miedo.

6) No tiene en cuenta las necesidades de Vd. (le deja el peor sitio de la casa, lo peor de la comida...).

7) Cuando se enfada llega a empujar o golpear.

8) Le dice que a dónde va a ir sin él/ella (que no es capaz de hacer nada por sí sola).

9) Le dice que todas las cosas que hace están mal, que es torpe.

10) Ironiza o no valora sus creencias (ir a la iglesia, votar a algún partido, pertenecer a alguna organización).

11) No valora el trabajo que realiza.

12) Delante de sus hijos dice cosas para no dejarle a Vd. en buen lugar.

13) Insiste en tener relaciones sexuales aunque sepa que usted no tiene ganas.

Se llega así a la cifra obtenida, que luego se extrapola al conjunto de la población. Se tiene asimismo en cuenta no sólo a quien tiene pareja en el momento de la encuesta sino el tipo de relaciones habidas hasta diez años atrás de la actualidad, es decir, se pregunta por parejas y exparejas, incluyéndose como hemos visto novios y no sólo maridos.

La Macroencuesta fue celebrada como un gran avance en el conocimiento de la problemática del maltrato y por lo que de implicación seria por parte de la Administración del Estado suponía. Las principales virtudes confesas del trabajo de 2000 eran la disposición por primera vez de información sobre malos tratos re- 
feridos a toda la población femenina mayor de edad, la amplia muestra utilizada - 20.552 mujeres fueron entrevistadas - y que aportaba datos sobre las variables de control asociadas a la experimentación de actos de violencia, a fin de establecer un perfil de las mujeres víctimas y sobre las consecuencias o sintomatología, tanto física como psicológica, producidas por tales actos (Instituto de la Mujer 2000: 3). En todo momento el trabajo compara a las mujeres maltratadas con el conjunto de la población de mujeres (así como a los varones maltratadores con el conjunto de los varones), con lo cual resulta plausible elaborar los perfiles de las situaciones de maltrato. Del mismo modo, el manejar la categoría de maltrato técnico permite detectar muchas situaciones de maltrato oculto, uno de los graves problemas a los que se enfrentan las políticas preventivas en este terreno. En relación con esto, es de agradecer que se profundice en la problemática del maltrato y no sea sólo de muertes de lo que se hable - muertes entendidas realmente como la punta del iceberg de un problema muy extendido, de hondas raíces y graves consecuencias-.

\section{2. ¿Es suficiente una sóla respuesta afirmativa «frecuentemente» o «a veces» para considerarlo maltrato?}

Ya hemos especificado que uno de los caminos para el incremento de las cifras de la violencia es la ampliación del concepto de maltrato. Ahora es el momento de analizar las implicaciones de dicha decisión. La distinción entre maltrato declarado y maltrato técnico descansa, como sabemos, en el reconocimiento directo o indirecto por parte de las mujeres de su situación particular de maltrato. La diferencia, pues, no reside en el tipo de maltrato recibido sino en la autoconciencia al respecto. En el caso de la Macroencuesta 2000, para asignar una situación de maltrato «técnico» el estudio se atiene a la definición sobre los distintos tipos de violencia que realiza el Consejo de Europa: violencia física, sexual, psicológica, económica y estructural, y sobre esas definiciones se hacen las preguntas. Las frases n. ${ }^{\circ s} 1,3,5,8,9,11$ y 12 reflejan situaciones de violencia psicológica, las frases $4 .^{\mathrm{a}}$ y $6 .^{\mathrm{a}}$, violencia estructural, la $2 .^{\mathrm{a}}$, violencia económica, la décimo tercera, violencia sexual, la $7 .^{\mathrm{a}}$, violencia física y por último, la $10 .^{\mathrm{a}}$ se refiere a violencia estructural. Para entrar en la categoría de maltratada (técnica) es suficiente haber contestado «frecuentemente» 0 «a veces» a alguna de las trece frases mencionadas. En una encuesta similar realizada en el año 2000 en Francia $^{24}$, un año después que la española, un hecho sólo se calificaba como agresión cuando se contestaba afirmativamente a tres de los interrogantes de los

${ }^{24}$ Encuesta «Nombrar y contar las violencias hacia las mujeres», de Maryse Jaspard y el equipo Enveff encargada por el secretariado de derechos de las mujeres y realizada por teléfono entre marzo y julio del 2000 con una muestra representativa de 6.970 mujeres El trabajo de campo de La Macroencuesta 2000 se hizo entre marzo y julio de 1999. Las cuestiones planteadas en dicha encuesta eran muy parecidas a las españolas, aunque abarcaba todo tipo de agresiones y no sólo las de ámbito doméstico (Badinter 2004: 17-18). 
que constituían presiones psicológicas, teniendo que ser una de las respuestas «frecuente» (Badinter 2004: 32-34).

La idea de distinguir entre uno u otro tipo violencia mediante diferentes definiciones de la misma no es exclusiva del maltrato. En los estudios de acoso realizados en el contexto europeo se pregunta, de forma similar, además de directamente por el acoso sufrido, indirectamente por situaciones de acoso recogidas en una batería de preguntas en las que no se lo menciona de forma explícita. «Mientras que hay bastante coincidencia en la acotación del "núcleo duro del acoso" - como las agresiones físicas o el chantaje sexual ${ }^{25}$-, no sucede lo mismo cuando se pretende medir ciertas situaciones del llamado acoso ambienta $^{26}$. Dentro de esta amplia categoría se pueden incluir desde miradas y chistes obscenos hasta el contacto físico indeseado. Y dado que no hay una línea divisoria férrea entre ciertas conductas sexistas y el acoso sexual, los datos finales variarán en función de lo que se incluya en la categoría de acoso: cuanto más detallada y exhaustiva sea la recopilación de experiencias y conductas, más elevados serán los resultados» (Pernas y Ligero 2003: 135). La consecuencia, en ambos casos, es que los episodios de violencia así registrados son mucho más numerosos.

En el caso de la Macroencuesta 2000, las cifras engordan más que la encuesta nacional francesa por el criterio de incluir como maltrato técnico una sola de las respuestas que se haya respondido como «a veces»: «Las mujeres Tipo A son aquéllas que hemos considerado maltratadas por haber respondido "frecuentemente" o "a veces" a, al menos, una de las trece frases escogidas de las veintiséis sobre las que se ha recabado información» (Instituto de la Mujer 2000: 8). De ahí las millonarias cifras que se manejan.

No es de extrañar, por tanto, que este tipo de formulaciones genere en la prensa grandes titulares referidos a los malos tratos, ya sin matizar si se trata de situaciones graves de violencia o de insultos y agresiones verbales muy imaginables en situaciones de pareja, por no mencionar las violencias que se salen de dicho marco ${ }^{27}$. La pauta para dicho tratamiento viene trazada ya por la propia dinámica del Instituto de la Mujer, que aunque en algún momento suaviza la fórmula al hablar de «cierto grado de violencia» o incluso de «vejaciones», el

${ }^{25}$ El chantaje sexual se produce cuando «la negativa o el sometimiento de una persona a dicha conducta se utiliza (en forma explícita o implícita) como base para una decisión que tenga efectos sobre el acceso de dicha persona a la formación profesional o al empleo, sobre la continuación en el mismo, los ascensos o cualesquiera otras decisiones relativas al empleo, obtención de una condición laboral o cese en el mismo» (Rubinstein 1987).

${ }^{26}$ El acoso ambiental se produce cuando la conducta de naturaleza sexual crea para quien la recibe un ambiente «humillante, hostil e intimidatorio» (Ibid.).

27 «Violencia doméstica/primeros datos de una macroencuesta a 20.000 mujeres. Cerca de 650.000 españolas son víctimas en la actualidad de malos tratos. Más de dos millones dicen haberlos padecido en algún momento de su vida», El Mundo, Sociedad, viernes, 4 de febrero de 2000 (cursiva nuestra). «Más del 11 por ciento de las españolas mayores de 18 años sufre malos tratos», $A B C$, Madrid., 17-12-2002. «Casi dos millones de españolas son víctimas de la violencia doméstica», El País, 18 de diciembre de 2002, Sociedad, p. 28. 
caso es que en lugares principales - objetivos y conclusiones - aparece sin matizaciones que se pretende "cuantificar los actos de malos tratos contra las mujeres... en el ámbito doméstico» (Ibid.: 3. Cursiva nuestra). ¿Es que acaso son todos de la misma naturaleza?

Sin duda, esta falta de matización a la hora de producir y presentar los datos favorece que incluso instancias habitualmente precavidas a la hora de manejar los datos que avalan sus denuncias como es Amnistía Internacional no reparen en grados de violencia cuando hablan de utilizar las leyes en los casos de las denuncias de las mujeres. En concreto, Amnistía acude a las cifras de las Macroencuestas de 2000 y 2002 para contrastar el número de maltratadas con las escasas denuncias que en relación a ese número observa: «... las mujeres que denuncian los abusos sufridos, a pesar de ser un porcentaje cada año mayor (73.109 mujeres), sigue siendo una minoría respecto del total de mujeres que sufren violencia de género» (entre 1.800 .000 y 2.000 .000 según oscilaciones de las encuestas citadas de 2000 y 2002) ${ }^{28}$ (cursiva nuestra) (Amnistía Internacional 2006: 13). Si Amnistía reflexiona sobre la necesidad de acudir a la ley será porque está pensando que las circunstancias son lo suficientemente graves como para ello, y sin embargo estos grandes números esconden situaciones de patente mala educación, agresiones verbales y abusos de poder pero que no todas indican necesariamente «actos de malos tratos», contrariamente a lo que dice la Macroencuesta. «La extensión del concepto de violencia a las agresiones verbales y a las presiones psicológicas... abre la puerta a cualquier interpretación» —-señala Badinter (2004: 32) —. En la Macroencuesta, reconocerse indirectamente como maltratada no gradúa por su gravedad las conductas incluidas bajo tal epígrafe respecto a las que se autodeclaran como maltratadas; fundamentalmente indica, como ya hemos comentado, el grado de autoconciencia.

\subsection{La amalgama de sexismo y maltrato}

La encuesta adolece de preguntas que mezclan en su formulación sexismo con maltrato, cuando no son lo mismo las actitudes sexistas - reflejadas en algunas de las preguntas- que el maltrato psicológico y menos aún que la violencia física, letal o no.

Dado, pues, que no hay una línea divisoria clara entre ciertas conductas sexistas y el maltrato en este caso -como también sucede en las situaciones de acoso- se efectúa de nuevo una amalgama que engrosa las cifras. Con ello se hace, por lo pronto, un flaco favor a quienes realmente están sufriendo violencia porque se está metiendo en el mismo saco el sexismo - que existe hasta en las me-

${ }^{28}$ Amnistía Internacional, Más derechos, los mismos obstáculos, Amnistía Internacional España, junio de 2006, p. 13. Bajo el título del informe se puede leer: «La protección efectiva de los derechos humanos de las mujeres un año después de la plena entrada en vigor de la Ley de Medidas de Protección Integral contra la Violencia de Género». 
jores familias - y el maltrato. Por otra parte, la no distinción entre uno u otro factor puede dar pie a presuponer que se está implicando que el sexismo conduce siempre a la violencia: para que haya violencia de género tiene que haber previamente sexismo pero la inversa no tiene por qué cumplirse — todo machista no es necesariamente violento-. Si esto fuera así la gran mayoría de las mujeres que tienen/han tenido parejas heterosexuales, en cuyo seno se dan habitualmente mayores o menores dosis de sexismo, serían mujeres maltratadas. Se produce de esta manera un error metodológico frecuente en las ciencias sociales como es el de suponer relaciones de causa-efecto en todos los casos de la población estudiada, lo cual no se corresponde con la realidad. Mutatis mutandis podemos ejemplificarlo con lo que sucede a menudo cuando se habla del proceso que conduce a la drogadicción: los expertos y desde las instituciones nos presentan una especie de camino inexorable (Osborne 1990: 72) que va desde el uso del cannabis - considerada droga blanda- a las drogas tachadas de duras - cocaína y heroína, entre otras-. Se nos presenta una parte de los datos -en algunos casos el recorrido va en efecto de una droga a la otra- por el todo, cuando en realidad el consumo del cannabis y de otro tipo de drogas se mantienen independientes entre sí en la gran mayoría de los casos. En el tema que nos ocupa, en primer lugar se mezclan sin explicación convincente bajo el leit-motiv de «todo es violencia» situaciones —insultos, sexismo, maltrato psicológico y violencia física- que son cualitativamente diferentes entre sí. En segundo lugar, implícitamente la Macroencuesta presenta como ineludible la escalada de hechos menos graves a los más graves en una relación de causa a efecto cuando ello es sólo parcialmente cierto. Se presentan como el todo las correlaciones estadísticas significativas en sentido directo del tipo «el sexismo se correlaciona con violencia», lo cual invisibiliza la parte que corresponde a las de sentido inverso tipo «el sexismo no se correlaciona con violencia».

Mayores precisiones conceptuales nos ayudarían a evitar estas confusas mezclas, imposibles de resultar operativas en los terrenos de legislación, educativas, de salud y políticas públicas. Muchas de las cuestiones que las macroencuestas denominan maltrato técnico coinciden con las que Luis Bonino, combinando una perspectiva foucaultiana con planteamientos feministas de género y las prácticas de terapeutas familiares feministas, ha denominado «micromachismos»: «las microviolencias — a las que he dado en llamar micromachismos- son pequeños, casi imperceptibles controles y abusos de poder cuasi normalizados que los varones ejecutan permanentemente... Son formas de dominación "suave"... Son de uso reiterado aún en los varones "normales", aquéllos que desde el discurso social no podrían ser llamados violentos, abusadores o especialmente controladores o machistas», que los emplean para perpetuar la situación de dominación sobre las mujeres que la cultura tradicional asigna a los varones (Bonino Méndez 2005: 87-88). La intención de Bonino es visibilizar estas conductas como un primer paso en la quiebra de las relaciones de dominio y la posterior andadura hacia unas relaciones más igualitarias. Se trata de dar herramientas a los terapeutas para desactivar estos mecanismos de opresión. La de- 
tección para prevenir situaciones de maltrato por medio de vías educativas y terapéuticas puede complementar a la vía judicial, tan en boga en nuestro entorno. Queda claro que hay mucho más machismo que violencia, pero puesto que se observa que las situaciones de maltrato se generan en un proceso y no de la noche a la mañana, resulta esencial la detección de situaciones tempranas de abuso - como proponen Bonino y muchos otros profesionales - en el sistema primario de salud. El objetivo es paliar sus efectos vía talleres reeducativos o terapéuticos, sin tener que esperar a situaciones más graves, donde necesariamente ha de intervenir la vía penal. Pero para ello se ha de partir de que no todo el micromachista será un maltratador más allá de su machismo recalcitrante.

\section{4. ¿Violencia en el ámbito doméstico, contra las mujeres, de género?}

Por otra parte en la Macroencuesta se investiga sobre la violencia en el ámbito doméstico, que incluye la de parejas y exparejas pero también la de otras personas del hogar - hijos/as propios o de las parejas, padre/madres y respectivas parejas, suegros e idem, hermanos-as/cuñados-as, otras personas de la familia y otras personas no familiares- . Aunque los porcentajes por uno u otro concepto se presentan por separado en el interior del trabajo, el caso es que, de nuevo, a la hora de las grandes cifras todo se amalgama en «violencia en el ámbito doméstico», lo cual si bien conceptualmente es correcto se presta a confusión si no se detallan bien los porcentajes respectivos. Y no estamos hablando de casos anecdóticos: entre las mujeres consideradas «técnicamente» como maltratadas, la mayor parte de los actos de violencia son causados por la pareja $(74,2 \%)$, cifra que baja en las mujeres que se declaran maltratadas (52\%), pero todo lo no englobado en esas cifras corresponde a otro tipo de relación más allá de la erótico-afectiva (Instituto de la Mujer 2000: 64).

De hecho, la Ley Integral no ampara en su concepción de la violencia de género la producida más allá de las parejas y exparejas masculinas, o sea, que la considera sustancialmente diferente. Sin embargo, los porcentajes sobre la procedencia de esta violencia diferenciada por quién la produce se obtienen con las mismas preguntas que las que catalogan la violencia de género. Cabría entonces preguntarse: ¿qué es lo que distingue a estos dos tipos de violencia? El resultado -los efectos- es el mismo: lo que las diferencia es quién la produce. Pero sin embargo a la hora de presentarlas se mezcla en un todo con el latiguillo «casi dos millones de mujeres sufren maltrato...».

Abundando en la pregunta: ¿es esto violencia de género? la respuesta es matizable si, por ejemplo, trazamos una divisoria respecto de quiénes causan la violencia en función del sexo - una parte de esta violencia es causada por mujeres. El único porcentaje que a la hora de los resultados es desagregado por sexo es el de la violencia producida por los padres y por las madres; pues bien, la violencia generada por las madres representa el $11,4 \%$ en cuanto al maltrato declarado se refiere, lo que equivale a 72.960 casos (frente a 70.400 de violencia por 
parte del padre) y un 12,8\% cuando, siguiendo los criterios de la Macroencuesta, el concernido es el maltrato técnico, lo que en cifras absolutas significa la nada despreciable cifra de 238.720 mujeres (251.775 si el maltratador es el padre) que manifiestan algún tipo de maltrato por parte de sus madres.

Podemos, pues, preguntarnos si es una violencia dirigida hacia mujeres por el hecho de ser mujeres para sojuzgarlas en tanto que tales o queda mejor explicada esta violencia por las diferencias de poder - por ejemplo la que va de padres/madres a hijas - o la falta de autoridad - de las madres respecto de los hijos/as- . Pero entonces, ¿cómo la denominamos? Y hecha la pregunta al revés, ¿qué es lo específico de la violencia de género que hace que todas estas violencias se excluyan de una ley que trata de proteger a las mujeres? María José Aguado, directora de un importante estudio sobre violencia escolar elaborado entre la Universidad Complutense y el Instituto de la Juventud, comentaba las semejanzas entre la violencia escolar y la violencia machista: «las dos se fundamentan en un modo de relación basado en el dominio y en la sumisión», añadiendo que en su estudio, los agresores justificaban más la violencia machista y racista ${ }^{29}$. Volviendo al caso que nos ocupa, ¿se trata de proteger a las mujeres de toda la violencia que reciban, o hay una jerarquía en el tratamiento hacia la violencia no por sus efectos —igual de «violentos» en los dos casos- sino por de dónde proviene? ¿Le duele más a una mujer el golpe o el insulto que le produce su hija o su hijo, su padre o su madre que el que le produce su novio o marido?

\subsection{Violencias perpetradas por mujeres}

Esto nos da pie a introducir uno de los temas tabúes sobre la violencia entre personas que conviven y es el de las violencias perpetradas por mujeres, en primer lugar contra otras mujeres. Todos los datos que se manejan públicamente para denunciar la violencia de género se enfocan siempre hacia la violencia de hombre a mujer. ¿Qué pasa con la violencia de mujer a mujer, sea de madres a hijas - abundante, como se desprende de los datos presentados-, de mujeres en parejas de lesbianas o entre chicas en los casos de acoso escolar? ¿Cómo la clasificamos? Si hablamos de violencia de género, es decir, la que se produce entre hombres y mujeres «en relación de pareja», ¿cómo calificaríamos la violencia física o el maltrato psicológico que producen las mujeres hacia los hombres —en pareja o con otro grado de parentesco-y los hijos varones? Las cifras - «menores» al lado de las grandes cifras que corresponden a la violencia de hombre a mujer - nos hablan de la violencia femenina, pero sin embargo a la hora del manejo de los datos por los expertos y, de paso, en el imaginario público, parece como si no existiera violencia por parte de las mujeres. ¿Qué sucede, pues, con

${ }^{29}$ Ana Alfageme, «M. José Díaz-Aguado/Experta en acoso escolar. Violencia escolar y machista son similares», El País, domingo 15 de mayo de 2005, Sociedad, p. 39.

EMPIRIA. Revista de Metodología de Ciencias Sociales. N. ${ }^{\circ}$ 15, enero-junio, 2008, pp. 99-124. ISSN: 1139-5737 
esta violencia, que se da de mujer a hombre, hacia otras mujeres, hacia las personas mayores, hacia la infancia? Que los resultados de esas cifras menores no vengan desagregados en las Macroencuestas indica la falta de voluntad de investigar ese tipo de violencia. Que en la de 2000 el $48 \%$ de las mujeres que se declaran maltratadas lo sean no por su pareja sino por otros familiares resulta altamente significativo. En el único supuesto en que este dato se ha desagregado por sexo ya hemos comprobado la magnitud de las cifras. ¿Qué cifras obtendríamos si se hubieran desglosado los demás supuestos? En la Macroencuesta 2006 el maltrato declarado era, como es lógico pensar, de nuevo causado mayoritariamente por la pareja o ex pareja - un 57,3\%-, pero si nos fijamos en «otros familiares», se repite que el único porcentaje desagregado por sexo es el maltrato causado por los padres - un 6,8\%-y por las madres -un 7,9\%-, que en cifras absolutas representa 53.510 mujeres que se declaran maltratadas por sus progenitoras. Si realizamos el mismo cálculo para las que el estudio conceptúa como maltratadas técnicamente, las cifras ascienden a 175.123 mujeres (el 9,8\% de las 1.786 .978 mujeres maltratadas técnicamente). No parecen cifras desdeñables. Sin embargo, en la parte extractada que ha realizado el Instituto de la Mujer respecto del Informe completo, el tema se despacha de la siguiente manera:

«Entre el total de las mujeres residentes en España de 18 ó más años, el $7,2 \%$ son mujeres consideradas "técnicamente" como maltratadas, y lo son por su pareja o expareja. Este porcentaje es menor que el obtenido hace cuatro $(8,7 \%)$ y siete años $(9,0 \%)$.

La proporción de maltrato técnico causado por otras personas del hogar no alcanza en ningún caso al 2,0\% de la población femenina mayor de edad.

En cuanto al maltrato declarado, según se observa en el gráfico siguiente, el $2.1 \%$ del total de mujeres de 18 años ó más son mujeres que se declaran maltratadas por su pareja/ex marido/ex pareja, proporción algo más baja que la obtenida en $2.002(2,3 \%)$.

El maltrato declarado causado por otras personas del hogar no sobrepasa, enningún caso, el 1,0\%.

Se puede concluir, pues, que la persona causante de la violencia doméstica es, en la mayoría de los casos, la pareja (ya sea la actual o el ex marido/ex pareja). Con respecto a hace cuatro años se produce una disminución de mujeres que se declaran maltratadas por su pareja» (cursiva nuestra).

Como se ve, el interés del estudio se orienta a expresar la disminución del maltrato a lo largo de los años y a minimizar la importancia de las otras violencias — las que no proceden de la pareja-.

En parecida línea, en el estudio comparativo por parte del Centro Reina Sofía para el Estudio de la Violencia se afirma que «como la violencia de género contra el hombre no es numéricamente significativa, habitualmente la expresión "violencia de género" se refiere sólo a la violencia contra la mujer. Así lo haremos también aquí» (cursiva nuestra), y no se menciona ninguna cifra que no 
responda a este criterio ${ }^{30}$. A nuestro juicio se podría haber señalado que las cantidades de una y otra violencia no son comparables ${ }^{31}$, de igual modo que la violencia de mujer a hombre no viene amparada por una ideología que apoya la dominación y el control a los hombres por parte de las mujeres, sin que ello rebajara un ápice la gravedad de la violencia de hombres a mujeres. De hecho, la realidad es muy tozuda en cuanto a la ideología que apoya la dominación de género: en un estudio realizado por María José Varela se analizaban 600 sentencias relativas a delitos contra la vida, malos tratos, agresión sexual, impago de pensiones y amenazas. «Por lo general» —-según la investigación- «cuando son ellos los autores del delito, las penas son más reducidas y las circunstancias atenuantes se aplican con mayor frecuencia, mientras que en los casos en que el sujeto activo es una mujer, las penas suelen aplicarse en su extensión más alta y las eximentes se toman en cuenta en contadas ocasiones ${ }^{32}$.

Cuando se analiza la violencia de mujer a hombre es evidente que la violencia física es mucho menor en estos casos, y cuando se produce, a veces es una violencia defensiva, pero no siempre. Nos referimos aquí a la violencia que se hace por sadismo, de forma consciente y para hacer daño. Algunos estudios que sí han analizado la cuestión hablan de que las mujeres son tan protagonistas como los hombres en el maltrato psicológico (García Quesada y Gomáriz Moraga 2004: 6-8). Las cifras de violencia hacia personas ancianas y niños son muy altas, y quienes en medida abrumadora cuidan a estos colectivos son mujeres. Así pues, la casuística nos muestra que hay mujeres que maltratan a su descendencia, matan a maridos ${ }^{33}$ e incluso a hijos ${ }^{34}$ y apoyan la violencia en las guerras ${ }^{35}$, como en el genocidio de Ruanda, en el que de los 120.000 acusados, 3.564 son mujeres (Badinter 2000: 83); torturan, como hemos visto en la cárcel iraquí de

${ }^{30}$ Centro Reina Sofía (ed.) (2007) II Informe Internacional. Violencia contra la mujer en las relaciones de pareja (estadísticas y legislación) (2007) Serie Documentos (vol. 11) http://www. centroreinasofia.es/

31 Esto, no obstante, resulta mucho más claro si lo referimos a la violencia física y la sexual; la violencia psicológica hay que tratarla con más matices. Vid. García Quesada y Gomáriz Moraga (2004).

${ }^{32}$ Marta Costa-Pau, «Severidad judicial con las mujeres», El País, Domingo, 5 de enero de 2002.

33 «Una mujer mata a su marido y lo entierra en un cortijo en Almería», El País, 10 de diciembre de 2005, Sociedad, p.26. «Una mujer degüella con un bisturí a su compañero sentimental en Girona» (subtítulo de la noticia), El País, 3 de enero de 2006, Sociedad, p. 32. «Un hombre muere apuñalado por su mujer en Toledo», El País, 13 de mayo de 2006, Sociedad, p. 32.

34 «Perder la vida a manos de los padres», El País, 21 de marzo de 2006, Sociedad, p. 46. Se describen los resultados de un estudio pionero en España realizado por la psicóloga clínica y forense Rosa Sáez Codina en la Universidad Autónoma de Barcelona sobre 31 sentencias judiciales de casos de filicidio con 42 víctimas. El estudio encontró que, generalmente, actúa un solo agresor, que en el $47,6 \%$ de las veces es la madre.

35 Como señala la historiadora británica Joanna Bourke, si las mujeres apenas han podido manejar directamente las armas, sí han podido imaginarse vicariamente en tal situación, sin los problemas de conciencia que pueden llegar a plantear a los combatientes los actos de crueldad (Bourke 1999).

EMPIRIA. Revista de Metodología de Ciencias Sociales. N. ${ }^{\circ}$ 15, enero-junio, 2008, pp. 99-124. ISSN: 1139-5737 
Abu-Grahib y antes ya nos enseñó el nazismo (Ibid.: 80-83) ${ }^{36}$; y, además, en las relaciones de pareja ejercen la violencia psicológica. Las agresiones por parte de los adolescentes, que está cobrando protagonismo en los últimos tiempos, incluye asimismo a las chicas, casi siempre contra otras chicas ${ }^{37}$. Del mismo modo, en las relaciones de pareja comienza a aflorar la violencia entre mujeres ${ }^{38}$.

Es decir, las mujeres pueden ser también muy violentas, a veces con violencia física directa, muchas otras con violencia más sutil, psicológica. Una pregunta central que nos debemos hacer en relación a la Macroencuesta sería la siguiente: si hablamos de violencia en el ámbito doméstico como se hace en la Macroencuesta, ¿qué pasaría si se hacen las mismas o parecidas preguntas a los hombres ${ }^{39}$ ¿Cuántas respuestas positivas sobre violencia ejercida de mujer a hombre obtendríamos si aplicamos los mismos criterios de cuantificación? Por parte del Instituto de la Mujer se proclama como una de las principales virtudes confesas del trabajo de 2000 (Instituto Mujer 2000: 3) la disposición por primera vez de información sobre malos tratos referidos a toda la población femenina mayor de edad. No hay el menor asomo de duda de la justeza de entrevistar sólo a mujeres, máxime que se ha hecho comparando a las maltratadas con el conjunto de la población femenina, pero nos tememos que la evidencia muestra que la violencia, sobre todo la psicológica, es patrimonio de ambos sexos ${ }^{40}$. Sólo preguntar a las mujeres y no a los hombres por la violencia que reciben parece estar presuponiendo como punto de partida que las mujeres son incapaces de maltrato y sin embargo hemos desgranado su capacidad para diversos tipos de violencias; con esta estrategia se sobreentiende de paso que los hombres son los únicos victimarios y que las mujeres sólo pueden ser víctimas - y nunca victimarias-; si no, ¿por qué no se intenta medir su potencial maldad?

${ }^{36}$ En España, en el caso de las agresiones grabadas en vídeo en una comisaría catalana, también aparecían dos mujeres policía «agrediendo» a una detenida. «Un vídeo policial muestra la agresión de dos "mosses" a una detenida en comisaría. (Subtítulo) Una policía abofetea a una joven que aparece esposada por la espalda y semidesnuda», El País, 31 de mayo de 2007, España, p. 31.

${ }^{37}$ Un estudio realizado en la Comunidad de Madrid sobre 4.600 escolares de 222 aulas de la región este mismo año (2005) señala que aunque su porcentaje es pequeño - 6\% — comparado con la violencia general detectada, «el número de chicas con un comportamiento agresivo en las aulas se ha duplicado». El País, martes 20 de septiembre de 2005, Madrid, pp. 1 y 3. Otra noticia de violencia entre muchachas adolescentes señalaba que Klara G. C. murió por cuchilladas de dos compañeras de Instituto en San Fernando, Cádiz. (Mención en El País, editorial, 17 de octubre de 2005, Opinión p. 14). Vid. Asimismo: «La policía investiga si el suicidio de una chica en Alicante se debió al acoso escolar. Los padres denunciaron hace cinco meses a varias compañeras por agredirla», El País, 3 de mayo de 200, Sociedad, p. 34. «El juez prohíbe a una niña de Elche acercarse al alumno al que agredió en tres ocasiones», El País, 21 de noviembre de 2006, Sociedad, p. 34.

${ }_{38}$ Maite Mateos, «Por el derecho al divorcio: la violencia en las parejas de mujeres lesbianas», Hika, 171/172, noviembre-diciembre de 2005, pp. 30-31. «Condenada una mujer a cinco meses de cárcel por violencia contra su ex compañera», El País, 28 de diciembre de 2004, Sociedad.

39 Badinter realiza la misma demanda en relación a Francia, p. 96. Según su testimonio, la encuesta Enveff «se refiere exclusivamente a la violencia que se inflige a las mujeres, y a nadie se le ha ocurrido formularles preguntas similares a los hombres» (Badinter 2004: 91).

${ }^{40}$ Es más, el prejuicio sexista suele afirmar que los hombres son más «noblotes» y directos y que las mujeres son mucho más retorcidas psicológicamente.

EMPIRIA. Revista de Metodología de Ciencias Sociales. N. ${ }^{\circ}$ 15, enero-junio, 2008, pp. 99-124. ISSN: 1139-5737 


\section{REFLEXIONES FINALES}

Persiste, pues, la tensión — bien que amable a estas alturas - entre los distintos sectores implicados como actores sociales en lo que a las cifras de asesinatos se refiere. Perduran los intereses divergentes, aunque las dos partes hayan acercado posturas.

Desde las instituciones parece preferirse que no aparezca en la contabilidad tanta violencia, se hable de muertas como de maltrato. Entre los posibles motivos podemos apuntar que puesto que con la Ley Integral el Estado asume públicamente su intervención como líder en el intento de contención de la violencia de género, cobra en su haber tanto los éxitos como los fracasos en la aplicación de dicha política. Una forma de medir tal cuestión es el aumento o la disminución de las mujeres en situación de maltrato así como de las muertes de mujeres. En los últimos años se ha efectuado una enorme labor para hacer aflorar la violencia oculta, que incluye el recuento de las agresiones que reciben las mujeres, como hemos narrado en estas páginas. En consecuencia, desde las Administraciones se necesita tener cifras importantes para que sus políticas sean tomadas en serio. Sin esta tarea no hay prevención ni intervención posibles, pero al mismo tiempo las cifras han de ser grandes ma non tropo porque entonces pueden parecer un fracaso de las tales políticas. El continuado desfase con las cifras de asesinadas obtenidas por las feministas avala esta hipótesis, así como el énfasis de la última Macroencuesta en la disminución de los números relativos al maltrato. En un contexto de importantes críticas al funcionamiento de la Ley Integral, resulta lógico que se prefiera no incluir todos los supuestos que desde los criterios feministas aquí presentados supondría la ampliación de las cifras de muertes y de su ámbito de intervención. Cabe reiterar, además, que si aumentan las cifras aumentan los gastos. Igualmente, destacar la rebaja del número de maltratadas apunta a subrayar el éxito de las políticas emprendidas.

Desde el feminismo y las ONG implicadas de una u otra forma en las cuestiones que tienen que ver con la violencia de género y la aplicación de la Ley Integral tiene sentido a su vez el continuo intento por ampliar los supuestos de la estadística y de la cobertura por parte de la Ley Integral. Su política de presión constante a la Administración ha contribuido al afinamiento de las estadísticas y a incluir en ellas casos que quedaban indebidamente fuera de la siniestra contabilidad de los asesinatos. Por otra parte, ello justifica su razón de existir y apunta a la posibilidad de expandir su espacio de influencia, obtenido de forma muy notable gracias a este ámbito de competencia y al éxito de su política de lobby.

El cuestionamiento constante de las cifras de muertes ha sido una forma, no sólo de ajustar los datos a la realidad sino que ha tenido como resultado llevar la discusión a la palestra pública y lanzar políticas. Del mismo modo, las Macroencuestas, al igual que se ha hecho en las situaciones de acoso, apuntan a una ampliación del concepto de agresión con parecidos resultados, con el interesante objetivo - y efecto- añadido de sacar a la luz situaciones de subordinación crónicas, ocultas incluso para las propias afectadas. Las cifras millonarias así ge- 
neradas engloban el sexismo profundo de estructuras sociales clave como son la familia o el entorno laboral, pero la dificultad y la ausencia en suma de distinción entre lo que sea sexismo en sentido amplio y violencia en sentido específico pervierten a nuestro entender las potencialidades de dichas evidencias.

El sexismo debería ser empleado como un contexto explicativo de la agresión pero no como una gradación de la misma. Mezclar todo en el mismo saco desdibuja los matices de una problemática muy amplia y las prioridades en las diferentes líneas de atención de las políticas públicas: las políticas de prevención y las de atención de la violencia allá donde ésta se produce. Los ámbitos educativo y sociosanitario de atención primaria corresponden más a la prevención mientras que al ámbito jurídico y asistencial compete el castigo de la violencia y sus secuelas de atención «integral» a las víctimas. Si bien es cierto que se están haciendo esfuerzos en todos los terrenos de intervención, la acometida mediante la vía penal de todas las situaciones donde se vislumbre alguna situación de maltrato tal y como éstas son definidas en sentido amplio, y que en la práctica incluye lo que Bonino denomina «micromachismos», crean un nuevo discurso que se percibe mayoritariamente como jurídico-proteccionista, y que discurre de arriba abajo desde el Estado a la sociedad, en detrimento de otros posibles enfoques que incidieran sobre todo en las fases educativas y de autoconciencia de la problemática que afecta a tantas mujeres ${ }^{41}$.

Algunas de las medidas emprendidas como la activación de los recursos públicos sólo si media denuncia legal merecen una atención particular. Ello significa que es posible que haya quienes recurran a este mecanismo legal aunque a lo mejor no lo tengan tan claro si quieren entrar en el circuito de las medidas de protección y demás mecanismo prescritos en la Ley Integral. Quizás esto ayude a explicar la retirada de muchas de las denuncias, la no solicitud de las órdenes de alejamiento o su incumplimiento frecuente por parte de las víctimas o la negativa a ratificar declaraciones previas, fruto del fragor de la disputa que haya servido de detonante en ciertos casos. Supone por otra parte, como ya hemos indicado, alzaprimar la vía penal frente a la vía sociosanitaria en el ámbito de la detección precoz de las situaciones de abuso, como argumentan a menudo los profesionales de estos ámbitos (Ruiz-Jarabo Quemada y Blanco Prieto 2005).

En el terreno que compete más directamente a las ciencias sociales cabe resaltar las implicaciones metodológicas de ciertas decisiones. Es evidente que si no hay preguntas no hay respuestas. Macroencuestas que sólo preguntan a las mujeres - y no a los varones - no permiten ajustar entre los sexos las situaciones reales de maltrato «técnico» no ya sólo en el seno de la pareja sino en el más amplio ámbito de lo doméstico. Amalgamar todas las agresiones sin puntualizar a la hora de presentar los resultados contribuye a reforzar indebidamente la ya de por sí grande cifra de los hombres maltratadores y a invisibilizar otras violencias que las mujeres no sólo padecen sino que también cometen. Matizar los resultados rompería la visión exclusivamente victimista de las mujeres cuya contrapartida ineludible es

\footnotetext{
${ }^{41}$ Vid. En esta línea a Larrauri (2007) y Maqueda (2007).
} 
la (excesiva) demonización de los varones. Como ya hemos señalado, en todo maltrato de hombre a mujer entendemos que hay sexismo pero no todo sexismo deriva hacia una situación de violencia. Con todo, el sexismo no es el único fundamento de la violencia ni de pareja ni en el ámbito familiar. En las situaciones en las que las mujeres cometen abusos o agresiones no habrá sexismo —que conecta con una situación social de dominación crónica de un sexo hacia el otro- pero sí una lógica de dominio y de control muy parecida, aunque sin el refuerzo social comentado. Cuando las circunscribimos a las relaciones de pareja desde luego que se juxtaponen con el ámbito de «las relaciones de género». Afrontar conceptualmente estas situaciones sigue siendo necesario porque podría ayudar a acercar las medidas que se emprendan a las situaciones «realmente existentes».

En los últimos años ha tenido lugar la coincidencia entre la parte más visible del discurso feminista $-\mathrm{y}$ las organizaciones correspondientes- con las políticas institucionales. El esfuerzo constante y reiterado de presentar a las mujeres primordialmente como víctimas $-\mathrm{y}$ a los varones como victimarios como obligada contrapartida - acucia la pregunta: ¿dónde queda en el planteamiento actual la agencia de las mujeres? Colapsar sexismo y violencia ha hecho cobrar excesivo protagonismo al ámbito jurídico, confiándose en exceso en su potestad para erradicar la violencia. Va siendo quizás hora de que las mujeres confíen, además, en su propia agencia.

\section{BIBLIOGRAFÍA}

Amnistía Internacional (2006): Más derechos, los mismos obstáculos, Amnistía Internacional España, junio.

Bonino MÉndeZ, L. (2005): «Las microviolencias y sus efectos. Claves para su detección», en Ruiz-Jarabo Quemada, Consue y Blanco Prieto, Pilar (directoras), op. cit., pp. 83-102.

CASTELls, M. (1998): «El fin del patriarcado: movimientos sociales, familia y sexualidad en la era de la información», en Castells, M., La era de la información (Economía, sociedad y cultura), Madrid: Alianza, pp. 159-269.

De Miguel Álvarez, A. (2003): «El movimiento feminista y la construcción de marcos de interpretación: el caso de la violencia contra las mujeres» Revista Internacional de Sociología, Tercera Época, n. ${ }^{\circ} 35$, pp. 127-150.

DuRÁN, M. A. (2007): «Los tiempos inciertos: el sueño, la memoria, la renovación y la muerte» en Roche Cárcel, J. A. (ed.) Espacios y tiempos inciertos de la cultura, Barcelona: Anthropos, pp. 120-132.

FERNÁNDEZ DÍAZ, N. (2003): La violencia sexual y su representación en la prensa, Barcelona: Anthropos.

García QuesadA, A. I. y GomáRIz Moraga, E. (2004): «Contra la violencia de género: cómo evitar un tratamiento pernicioso», San José de Costa Rica, Fundación Género y Sociedad (GESO), junio. www.generoysociedad.org.

INMARK. Estudios y Estrategias S.A. (2006): El acoso sexual a las mujeres en el ámbito laboral: resumen de resultados, Madrid, Ministerio de Trabajo y Asuntos Sociales, Secretaría General de Políticas de Igualdad, Instituto de la Mujer, abril. 
InSTITUTO DE LA MuJER (2000): La violencia contra las mujeres. Resultados de la macroencuesta, Madrid, Ministerio de Trabajo y Asuntos Sociales, Instituto de la Mujer.

LARRAURI, E. (2007): Criminología crítica y violencia de género, Madrid: Trotta.

LAURETIS, T. de (1987): Technologies of Gender. Essays on Theory, Film, and Fiction, Londres y otros, The MacMillan Press LTD.

MAquedA, M. ${ }^{a}$ L. (2007): «¿Es la estrategia penal una solución a la violencia contra las mujeres?: algunas respuestas desde un discurso feminista crítico», InDret, revista para el análisis del Derecho, $\mathrm{n}^{\circ} 123$, octubre.

MARUGÁn, B.y VeGA, C. (2001): «El cuerpo contra-puesto. Discursos sobre la violencia contra las mujeres», en Bernárdez, A. (ed.): Violencia de género y sociedad: una cuestión de poder, Madrid, Instituto de Investigaciones Feministas y Ayuntamiento de Madrid, Área de Promoción de la Igualdad y Empleo, pp. 109-133.

OSBORNE, R. (1990): «¿Existe una relación causal entre pornografía y violencia?» en Calderón, M. y Osborne, R. (eds.), Mujer, sexo y poder (Aspectos del debate feminista en torno a la sexualidad, Madrid: Proyecto «Mujer y poder», Instituto de Filosofía. CSIC, Fórum de Política Feminista, Comisión Antiagresiones del Movimiento Feminista.

- (2004): «Del padre simbólico al padre real: la función paterna desde la modernidad», en de la Concha, A. y Osborne, R. (eds.): Las mujeres y los niños primero (Discursos de la maternidad), Barcelona, Madrid: Icaria y UNED.

Osborne, R. y Justo SuÁREZ, C. (2004): «Ser mujer en la guerra», en Roldán, C., Ausín, T. y Mate, R. (eds.): Guerra y paz en nombre de la política, Madrid: Calamar ediciones, Colección «El rapto de Europa».

RuIZ-JARABo QuemadA, C. y Blanco PRIETO, P. (directoras) (2005): La violencia contra las mujeres. Prevención y detección, Madrid: Ed. Díaz de Santos.

TERRASSON, B. (2003): «Las violaciones de guerra y las mujeres en Francia durante el primer conflicto mundial: 1914-1918», en Nash, M. y Tavera, S. (eds.): Las mujeres y las guerras. El papel de las mujeres en las guerras de la Edad Antigua a la Contemporánea, Barcelona: Icaria (Colección Antrazyt), pp. 306-325.

Vives, I. (2001): «Las políticas públicas desde la Administración del Estado» en Osborne, R. (coord.): La violencia contra las mujeres (realidad social y políticas públicas), Madrid, UNED, Colección Varia, pp. 79-91.

\section{RESUMEN}

Desde finales de los años noventa del pasado siglo, cuando en España se tomó conciencia sobre la gravedad del fenómeno de la violencia de género, las Administraciones Públicas, empujadas por el feminismo, han ido afinando las herramientas conceptuales y estadísticas a fin de lograr la contabilidad imprescindible para la intervención pública. A partir de lo que se incluya bajo esta rúbrica se ha de distinguir entre «la violencia de género» $\mathrm{y}$ «las cifras de la violencia»: entre la definición «abstracta» de la violencia y las cifras median los «indicadores» de qué se considera violencia, y ello depende en buena parte, en primer lugar, de la toma de conciencia del problema y, en segundo lugar, de los diversos intereses en liza; en definitiva, es una cuestión política. En el presente artículo analizaremos las razones de sucesivas ampliaciones de las cifras de la 
violencia y revisaremos críticamente algunas de las transformaciones conceptuales que las han acompañado.

\title{
PALABRAS CLAVE
}

Violencia de género, cifras de la violencia, Instituto de la Mujer, feminismo, macroencuesta.

\begin{abstract}
From the end of the last century Spain became conscious of the seriousness of gender violence. Thereafter and under the influence of feminism, the Establishment set conceptual and statistical tools to reach the necessary accounting to undertake public policies. According to what is included in the definition of violence it might be necessary to distinguish between «violence» and the «violence data»: in between we find the «indicators» of what is meant by violence. This depends, on the one hand, of the consciousness of the problem; on the other hand, of the different interests involved. In sum, it is a political issue. In this article we will analyse the reasons behind the constant broadening of violence data. We will also revisit with a critical vision some of the conceptual changes which have taken place.
\end{abstract}

\section{KEY WORDS}

Gender violence, violence data, Women's Institute, feminism, macrosurvey. 